\title{
O tempo da falta e o tempo da bonança: experiências de cronicidade na Guariroba, Ceilândia/DF
}

A time of shortage and a time of bonanza: Experience of chronicity in Guariroba, Ceilândia/DF

\section{Soraya Fleischer e Monique Batista}

\section{(2) OpenEdition Journals}

\section{Edição electrónica}

URL: http://journals.openedition.org/aa/584

DOI: $10.4000 / a a .584$

ISSN: 2357-738X

\section{Editora}

Programa de Pós-Graduação em Antropologia Social (UnB)

\section{Edição impressa}

Data de publição: 31 dezembro 2013

Paginação: 195-224

ISSN: 0102-4302

\section{Refêrencia eletrónica}

Soraya Fleischer e Monique Batista, "O tempo da falta e o tempo da bonança: experiências de cronicidade na Guariroba, Ceilândia/DF», Anuário Antropológico [Online], v.38 n.2 | 2013, posto online no dia 01 fevereiro 2014, consultado o 28 abril 2021. URL: http://journals.openedition.org/aa/584 ; DOI: https://doi.org/10.4000/aa.584

Este documento foi criado de forma automática no dia 28 abril 2021.

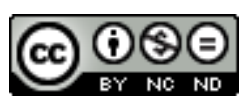

Anuário Antropológico is licensed under a Creative Commons Atribuição-Uso Não-Comercial-Proibição de realização de Obras Derivadas 4.0 International. 


\title{
O tempo da falta e o tempo da bonança: experiências de cronicidade na Guariroba, Ceilândia/DF
}

\author{
A time of shortage and a time of bonanza: Experience of chronicity in Guariroba, \\ Ceilândia/DF
}

Soraya Fleischer e Monique Batista

\section{NOTA DO EDITOR}

Recebido em 23/07/2013

Aceito em 30/09/2013

\section{Introdução: nas fímbrias da memória}

1 Desde 2008, temos circulado e convivido com interesses de pesquisa no bairro da Guariroba, localizado na Ceilândia, cidade do Distrito Federal. o foco tem repousado nas vivências de idosos com "doenças compridas", como uma senhora bem caracterizou os problemas de pressão, de diabetes, derrame e AVC, por exemplo. ${ }^{1}$ Assim, a partir da antropologia da saúde, no presente artigo, tentaremos fazer dialogar dados sobre os sofrimentos patológicos e sociais com outros dados referentes às mudanças urbanas vivenciadas no Distrito Federal nos últimos 40 anos. Embora não sejamos estudiosas da antropologia urbana, vamos nos beneficiar de boas reflexões deste campo. Pode ser rentável perceber como aspectos da saúde perpassam e são impactados pelas características das cidades e das vivências urbanas. 
2 Vale ressaltar que, ao conversar com pessoas com mais de 60 ou 70 anos de idade, estamos navegando pelas fímbrias vivas e sempre (re)construídas da memória. Orientamo-nos aqui pela obra de Myriam Lins de Barros, que muito trabalhou com senhores e senhoras idosos na cidade do Rio de Janeiro. Ela nos diz que "a memória, também elaborada no presente, faz um trabalho seletivo das lembranças. É o lugar social no presente que define o caminho das lembranças. Portanto, a linguagem do presente constrói passado e futuro" (2006:22). Fica claro que os relatos compartilhados conosco nos últimos anos e, muitas vezes, localizados nas primeiras décadas de criação da capital federal são versões elaboradas no presente e para uma plateia específica. Poderíamos parafrasear a autora para o contexto dessa pesquisa: "O modo de vida na cidade desse tempo contrasta com o viver [na Guariroba] de hoje, tomado, então como parâmetro" (1999:47). Ao longo do presente texto, será visto como os tempos passado e presente, bem como os espaços iniciais e atuais da Guariroba são comparados com intensidade.

3 Para além das histórias de vida, vale pensar também suas repercussões interpretativas sobre uma geração e uma cidade:

A construção da imagem da cidade realizada pela narrativa da memória, embora partindo de pontos de vista diferentes que dizem respeito ao lugar social que o(a) narrador(a) ocupa e ocupou ao longo de sua trajetória de vida, acaba convergindo para alguns pontos comuns que permitem pensar o universo investigado como parte de uma geração que viveu situações sociais próprias e distintas de outras faixas etárias. A importância da cidade se faz sentir nas lembranças não como uma entidade em abstrato, mas como experiência de vida. Esta experiência recorta a cidade em pedaços, fazendo de um bairro, de brincadeiras de crianças, de jogos de futebol em terrenos baldios do subúrbio do Rio a própria cidade (Lins \& Barros, 1999:45, grifos meus).

4 Assim, o trabalho de Lins de Barros nos ajuda a perceber como a memória só consegue percorrer o tempo porque navega, com o olhar e a observação, pelas mudanças no espaço:

As imagens misturam-se aos sons, aos odores, à sensação de frio e calor, construindo, assim, o quadro de lembranças de uma cidade. O lugar, nos diz Halbwachs (1990), é fundamental para situar nossas recordações e nossos sentimentos. Sem a dimensão do espaço ficaria difícil recordar (Lins de Barros, 1999:48).

5 Nas seções seguintes, ao narrarmos sobre as transformações notadas nas casas, nas ruas, nos bairros e nas cidades do DF, sugeriremos que as pessoas que temos conhecido estão nos comunicando a respeito de como percebem a passagem do tempo de suas vidas e, inclusive, de seus corpos. O grande desafio é: como manter as lembranças quando os marcos espaciais vão mudando a ponto de sumirem? Atentar para o que é contado por pessoas mais velhas também tem o papel de captar, reter e discutir cenários que não mais podem ser identificados imediatamente pelas plateias ouvintes, mas que continuam constitutivos das vidas dessas pessoas, mais velhas ou mais jovens. De alguma forma, artigos que articulem memórias como estas podem ajudar nas reflexões sobre a construção das diferentes Brasílias contidas no DF e também sobre as percepções acerca do envelhecimento desses corpos narradores. Assim, propomos que corpos, espaços e tempos estejam em inter-relação nesses relatos bem como em nossas análises.

6 Ainda assim, não pretendemos cristalizar os enunciadores, seus relatos e doenças e tampouco seus bairros e cidades como tipos sociais, ou mesmo sugerir que possam ser 
completamente compreendidos pelas versões situadas e circunscritas que nos foram oferecidas nas conversas. Neste ponto, claramente, eles e nós nos equivalemos em nossa enunciação parcial ao mundo. Os interlocutores escolheram, a partir deste século XXI, o que nos contar de suas trajetórias de migração até o Distrito Federal; ao passo que nós também selecionamos, a partir do que ouvimos e temos lido, o que discutir aqui. São excertos que criam imagens sobre as experiências de padecimento, habitação e envelhecimento. De alguma forma, esses excertos talvez possam contribuir para a linha de Patriota de Moura, que relaciona "processos de crescimento urbano a trajetórias pessoais narradas em relatos autobiográficos” (2010: 110).

7 Para tanto, é preciso ressalvar que tentaremos evitar uma ideia unívoca de "cidade", bem como de "bairro". A ideia de "cidade" no DF é diferente daquela de outras localidades chamadas pelo mesmo nome ao redor do país. Mas é bom lembrar que a Ceilândia, assim como outras localidades do DF, já foi chamada por muito tempo de "cidade satélite", numa clara alusão de dependência, inclusive simbólica, ao Plano Piloto, no centro da capital. Houve uma passagem proposital para os termos "região administrativa" e "cidade". Muitas localidades mais recentes já nasceram no tempo das "RA":

O status de "cidade" tornou-se importante elemento de reivindicação por parte dos moradores de áreas de baixa renda. [...] Se as "cidades satélites" são hoje chamadas simplesmente de "cidades", isso se deve a sucessivos processos de emancipação simbólica desses territórios. Não obstante, a categoria "Brasília" é simbolicamente englobante e refere-se ora ao Plano Piloto e áreas adjacentes, sendo uma região administrativa entre outras, ora ao DF como um todo. Mais do que designar uma área geográfica, Brasília aparece como categoria simbolicamente relevante para os que habitam diferentes "cidades" do DF (Patriota de Moura, 2010:296-297).

8 Assim, Brasília é uma cidade que abrange outras, que também se designam como cidades. Dentro de cada uma há bairros, setores, centros etc. e, quiçá, no futuro, até novas cidades. À frente, em diálogo com os dados etnográficos, esperamos poder ponderar também sobre o termo "bairro". Por enquanto, guardamos a orientação de que "cidades" devam ser entendidas

as being multidimensional and multi scalar assemblages (Sassen, 2006; Roy \&Ong, 2011) which, in their material dimension, occupy and territorialize spaces. In so doing, these assemblages also produce lives and meanings through which people weave their paths of life (Patriota de Moura, 2011:503).

9 Com esta perspectiva, a Ceilândia, criada em 1971, é hoje a cidade mais populosa do DF. Sua grandeza se reflete em sua diversidade populacional, em termos de origem, classe, geração e territórios. Ela dista $35 \mathrm{~km}$ do Plano Piloto e é acessível por grandes artérias rodoviárias para veículos particulares e coletivos, como ônibus e metrô. Há uma migração interna pendular diária, já que grande parte dos empregos se situa no centro da capital. Mais e mais, contudo, a Ceilândia e suas vizinhas - Brazlândia, Taguatinga, Águas Claras - têm se convertido em espaços de trabalho também. Desde 2008, frequentamos um de seus maiores e mais antigos bairros, a Guariroba. A região da Guariroba nasceu de uma fazenda homônima que foi desapropriada e essas terras "passadas [...] para o patrimônio da Novacap (Companhia Urbanizadora da Nova Capital), passou o Estado, proprietário fundiário, a loteá-las e vendê-las" (Oliveira 1987:130 apud Borges, 2004:41, nota 6). Contudo, como se verá abaixo, no início da década de 1970, parte da Fazenda Guariroba não teve "lotes" vendidos, como é bastante comum no DF, mas casas populares construídas e subsidiadas pelo governo da capital. 
10 Nesse tempo, temos frequentado, sobretudo, um dos três centros de saúde localizados no bairro, que nos faculta acesso aos seus corredores de espera, salas de acolhimento, consultórios, grupos de apoio e de ginástica. Além disso, recorrentemente, passamos às casas, fazendo uma proposital guinada dos "usuários" aos "moradores" ou simplesmente "pessoas" que construíram o que hoje chamam de Guariroba. Geralmente, estabelecemos conversas pautadas por nossas perguntas, mas sempre permeadas pelas agendas apresentadas pelas pessoas que vamos conhecendo. Fazemos anotações em campo, transcritas em seguida para diários de campo mais extensivos, habitualmente compartilhados, em suas versões editadas, com os estudantes partícipes da equipe, com fins didáticos, mas sobretudo para compor um quadro empírico do qual todos se beneficiam. Assim, este artigo bebe da meia dúzia de tomos de diários de campo que elaboramos nos últimos anos.

\section{A chegada a Guariroba}

11 Em geral, os livros que contam a história do Distrito Federal de forma mais crítica já questionam as narrativas oficiais. Evitam reproduzir imagens unicamente positivas das experiências de construção da capital federal, e o livro de Ribeiro (2004) é um belo exemplo de uma perspectiva que não glorifica a construção de Brasília e que tampouco ouve apenas as vozes dirigentes. A criação da Ceilândia, nesta mesma linha crítica, é recontada a partir das iniciativas de remoção compulsória dos trabalhadores imigrantes que haviam se organizado em vilas e acampamentos, mas que eram indesejados e impensados no espaço previsto para o Plano Piloto, região central e prestigiosa do território da capital (Resende, 1985). Nesse sentido, há muitos relatos sobre a destruição de barracos e a transferência forçada de cerca de 80 mil pessoas para um espaço desabitado e sem qualquer urbanização, o que equivale atualmente ao território da Ceilândia Norte. Essa experiência também se repetiu à época em outras cidades do DF, como Costa mostrou no caso da criação da Vila Buritis, em Planaltina (1978) e, nos anos 1990, no Recanto das Emas (Borges, 2004:24), por exemplo. Borges mostra como, mesmo recentemente, o objetivo das "remoções" continua a passar ao largo de questões de direitos humanos, habitação e urbanização. Patriota de Moura, em seus estudos sobre o crescimento de Brasília, lembra:

No caso de Brasília, diferentes autores já demonstraram as relações de dependência entre a cidade modernista materializada no Plano Piloto de Brasília, o centro da capital, e sucessivas levas de ocupações clandestinas ou irregulares, seguidas de outras levas de ações governamentais no sentido de erradicar "invasões", assentar populações "faveladas" ou mesmo atrair ou afastar ondas de migração de populações de baixa renda (2010:282).

12 A estratégia da "remoção", como planejamento, mas também limpeza urbana, é encontrada nos processos de expansão urbana ao redor de todo o Brasil, desde o início do século XX, já no governo Vargas (Cavalcanti, 2009; Bonduki, 1994). Num segundo momento, Cavalcanti mostra, a partir do caso do Rio de Janeiro, como os investimentos mais recentes de urbanização dessas novas áreas habitacionais tratam de uma "história de mudança de paradigma das políticas governamentais calcadas na remoção para programas que visam à 'integração' da favela à cidade dita 'formal' [que] pode ser lida como a história da passagem do 'barraco' de estuque para a 'casa' de alvenaria" (2009:72). No DF, embora as remoções tenham desacelerado e a integração urbana 
tenha sido mais a tônica, mesmo a passos lentos, remoções ainda acontecem e aquelas do passado firmaram-se na memória de muitos moradores da capital.

No entanto, entre as pessoas com quem temos conversado e convivido na Guariroba, não aparece um único relato de expulsão violenta do Plano Piloto. $O$ caminho que essas pessoas tiveram na migração externa e depois interna foi distinto e, a nosso ver, revela informações importantes para entender como estão hoje esses idosos e como suas histórias de vida repercutem em sua saúde, mais especificamente nas "doenças compridas" com que tantos precisam conviver. Passemos, portanto, à especificidade deste conjunto de cerca de 50 pessoas que integram esta pesquisa. Embora a Guariroba não seja identificada em sua história por "ocupações clandestinas ou irregulares" e o bairro não nasça no marco da ilegalidade fundiária, temos ali um exemplo do que Patriota de Moura (2010) chamou acima de "ações governamentais" para promover a "habitação social", conforme Bonduki (1994). ${ }^{2}$

É importante situar esses idosos contatados em termos de tempo e espaço, as tônicas orientadoras deste artigo. A trajetória de tais imigrantes começa com a saída de seus estados de origem, em geral Ceará, Paraíba, Piauí, Bahia e Minas Gerais, conforme as conversas informais e também os dados quantitativos encontrados nos prontuários do Centro de Saúde. ${ }^{3}$ Na transição entre as décadas de 1960 e 1970, vieram quase sempre sozinhos e solteiros, por volta dos 20 anos de idade, em busca de mais oportunidades de trabalho, renda e moradia no DF. Alguns poucos já chegaram casados e com filhos bem pequenos. Seu Paulo resumiu o espírito da época: "Vim foi buscar a vida, a sorte". Mas não vieram sem contatos, o que é fundamental para oferecer a primeira recepção, o primeiro emprego e, sobretudo, a apresentação a uma rede de conhecidos, a partir da qual surgem candidatos a namorados, noivos e cônjuges, bem como amigos e toda sorte de pessoas que podem ser úteis para encontrar melhores trabalhos, moradia, informações sobre serviços de saúde, educação etc. (Ribeiro, 2004, cap.2).

15 A maioria trabalhou com a construção civil, no caso dos homens, e no espaço doméstico, como empregadas, cozinheiras, passadeiras, diaristas, babás, no caso das mulheres. Algumas aproveitaram a vinda das famílias para quem já trabalhavam no Nordeste e, aqui, continuaram por algum tempo nesse acordo, até perceberem que havia condições melhores em termos de salário e direitos trabalhistas em outras "casas de família". Encontramos algumas que eram costureiras nas casas dos outros e, depois, em seu próprio ateliê, e poucas que estiveram nos serviços públicos (como merendeiras, faxineiras, "serviços gerais").

16 Muitos dos filhos dessas pessoas nasceram no DF e sempre nos chamou a atenção como a memória, principalmente das mulheres, era reconstruída em paralelo à trajetória reprodutiva. Gestações, partos, abortos, histerectomias, por exemplo, ajudavam a lembrar de quando se havia chegado à cidade, mudado de casa, o marido conseguido um emprego melhor etc.

Ao largo de todas essas mudanças no grupo doméstico, acontecia um trânsito importante dentro do DF. Usualmente, essas 50 pessoas, primeiro, chegaram para viver em Taguatinga e, em menos casos, no Núcleo Bandeirante e Sobradinho. Em comparação com o que deixaram para trás (no Nordeste ou no norte de Minas Gerais) e o que encontrariam pela frente (na Ceilândia Norte ou na Guariroba), os primeiros anos em Taguatinga são rememorados com muita positividade: "Lá em Taguatinga tinha tudo, asfalto na porta, ônibus, tudo" (D. Eva). Contudo, um ou outro lembra que Taguatinga tampouco era uma cidade tão estruturada como a maioria parece pintar; 
também havia limitações urbanas, como lembra D. Dolores: "Quando eu cheguei, eu fui pra Taguatinga. Era um frio pra cá! Um frio! Lá, era só uma padaria, um açougue, um ponto frio e o Bar Estrela. Só isso que tinha". Mas Taguatinga tendia a figurar como um bom lugar para se viver naqueles idos de 1960.

De Taguatinga, nossos entrevistados seguiram duas possibilidades. A primeira delas dizia respeito a fugir dos aluguéis que inflacionavam na medida em que Taguatinga se desenvolvia com celeridade e, por esta razão, muitas pessoas foram morar em barracos mais econômicos na Ceilândia Norte. Nessa nova cidade que surgia no início dos anos 1970, era na parte norte que havia casas para serem alugadas. A segunda possibilidade era sair do "sofrimento do aluguel", como uma senhora chamou, e passar a uma moradia própria. $\mathrm{E}$ as casas populares subsidiadas que começavam a ser construídas na Guariroba, já na Ceilândia Sul, foram uma grande oportunidade nesse sentido.

Alguns entrevistados contam que souberam dessa alternativa e fizeram de tudo para "se inscreverem no cadastro da SHIS". ${ }^{4}$ Outros receberam os funcionários da SHIS espontaneamente na casa em que moravam à época, já que houve também uma divulgação ativa desse programa por parte do GDF. Assim, muitos conseguiram sair do aluguel ao encontrarem seus nomes nas listas anunciadas nos jornais de tempos em tempos, ao longo de toda a década de 1970. Estas listas eram compostas pelos nomes das pessoas inscritas na SHIS e que haviam sido sorteadas para receber uma casa popular na novíssima Guariroba. Desta forma, diferente dos que foram desalojados das vilas do Plano Piloto, nossos entrevistados saíram de Taguatinga para morar em casa própria na Guariroba (Ceilândia Sul), passando ou não uma temporada em barracos de aluguel na Ceilândia Norte. Esta foi a trajetória mais comum daqueles que temos conhecido, desafiando tanto as narrativas assépticas que só apresentam a chegada do funcionalismo público às quadras padronizadas do Plano Piloto quanto as narrativas de expulsão violenta das vilas de trabalhadores localizadas nesse mesmo espaço. Ao que parece, esses moradores que hoje vivem na Guariroba seguiram um caminho de crescimento um pouco mais autônomo, pagando aluguéis e depois prestações, com pouco enfrentamento da autoridade estatal.

20 Assim, a Guariroba parece guardar uma perspectiva mais positiva sobre o surgimento da Ceilândia se considerarmos os relatos brutais de expulsão, remoção, realocação compulsória. Além disso, embora as pessoas ressaltem para nós que "ganharam" as casas ali no bairro, muitas das senhoras entrevistadas fazem questão de contar como tiveram que convencer os maridos a fazerem a "inscrição da SHIS" ou a comprar o jornal diariamente para conferir o resultado do sorteio. Ademais, não exatamente "ganharam", já que as casas foram todas quitadas depois de um longo período de módicas prestações. É preciso cautela ao ler os dados sobre as casas recebidas, pois a dádiva parece se referir à sorte com que contaram no momento da escolha, mas não exatamente o fato de receberem algo sem ônus ou sem esforço.

\section{0 tempo da falta: bichos, mato, poeira e carros-pipa}

Os relatos geralmente positivos sobre a primeira estadia no DF, em Taguatinga, confrontam-se claramente com os relatos negativos sobre a chegada a Guariroba, embora ainda nos anos 1970 eles se assemelhassem àqueles em outras áreas do Distrito Federal ou de outras cidades brasileiras, em que casas ou apenas lotes 
"semiurbanizados" (Borges, 2004:36) foram entregues. A falta de asfaltamento e de “água limpa" (:42, nota 16)são recorrentes nas memórias:

$\mathrm{Na}$ Ceilândia Norte, o lote era maior. Tinha quintal, era muito bom. Lá, naquela época, já tinha asfalto, já tinha luz e tudo. Aqui, não tinha era nada. Era bem difícil. (D. Miriam)

Aqui na Guariroba, eu me lembro bem, quando a gente mudou pra cá, era tudo uma graminha só. Eu encontrava cobra aí na porta de casa. (D. Marta)

E tinha carência de muita coisa. Não tinha farmácia. Se a gente precisava comprar algum remédio, a gente tinha que ir lá na farmácia da Ceilândia Sul, lá em cima. Ponto de ônibus também não tinha aqui. Quando a gente queria pegar condução, tinha que ir para lá também. E comércio também era bem pouco. Telefone, então, deus me livre, que ninguém tinha telefone na época. Só tinha um orelhão. E quando a gente precisava dar um telefonema, era uma fila que... E corria o risco dele não prestar, porque quase sempre tava com defeito, ou alguém depredava. Aí, era sufoco. (D. Deusdete)

Aí, um dia, passou gente lá fazendo a inscrição da SHIS. E a gente fez. Aí, saiu essa casinha aqui pra gente. Mudamos para cá. Mas não tinha luz na rua, não era murado nem nada. Era tudo de terra aqui, só vendo. Era bem difícil. Aqui no fundo do quintal, era mato tudo. Não tinha ônibus, a gente tinha que fazer tudo a pé. (D. Marieta)

Na verdade, essas narrativas são muito semelhantes àquelas que outros pesquisadores ouviram de pessoas chegando a "novos" espaços para morar. Só para ilustrar, dada a semelhança, cito o trabalho de Mariana Cavalcanti: "Proliferam-se relatos da chegada ao Rio de Janeiro de famílias de migrantes que, quase sem exceção, se espantam com o 'mato', a ‘selva', o 'ermo' nas cercanias de seus barracos” (2009:73).

Uma das alusões mais frequentes a essa falta de infraestrutura urbana se remete à água:

Lembro que a água a gente pegava na escola, essa escola que tem aqui do lado. (D.

Mariana)

Era uma torneira para todos os moradores. (D. Nicole)

Água também, quando a gente chegou aqui, água tinha que sair para pegar em algum lugar. Quanto mais alto, menos a água vinha. A gente ia buscar água nas casas debaixo. Não era sempre, mas tinha. Porque, mais embaixo, mais capacidade, mais pressão para subir. Eu carreguei muita lata d'água. Eu cheguei aqui grávida, de barrigão, e tinha que sair atrás. Era o jeito, né? E também tinha umas caixas de água. $O$ carro pipa punha e a gente pegava. (D. Deusdete)

A dificuldade que se apresentava a essas pessoas na Guariroba era a de encarar uma realidade muito distante da prometida "casa própria". Imaginavam que, além de uma casa "nova em folha", também receberiam ruas, transporte, iluminação e saneamento básico. Diferente dos "removidos à força do Plano", aqui a violência estatal foi de outra ordem, no oferecimento de apenas uma "casa da SHIS" e não um "bairro da SHIS". Embora a expectativa imediata fosse a de "sair do aluguel" e ter a "casa própria", parece que a ideia de um "bairro" em termos de calçadas, escolas e centros de saúde também estava associada à de "moradia". Entendemos que, ainda que em construção, para além de bairro (Guariroba) e da cidade (Ceilândia), houvesse sobretudo a expectativa de que fosse "urbano", nos termos de Patriota de Moura: os moradores "aspiram a ser 'urbanos' no sentido de ter dignidade urbana, reconhecimento moral (embora raramente legal) e participação política" (2010:506, tradução minha). Seu Geraldo, um mestre de obras aposentado hoje em dia, estranhou essa urbanização inexistente:

Quando a gente chegou aqui, era brabo. Ali em cima, onde tem aquele lava-jato, tinha o escritório da SHIS. A gente passava lá para pegar a chave da casa nova, para 
entrar na casa. A gente chegou aqui, tinha chovido e uma lama tinha entrado aqui pelo portão e na casa toda, até sair pela porta da cozinha lá atrás. Eu falei: "Eu não vou morar num lugar desse". Minha mulher falou: “Ah, vai sim. Vamos ficar. Depois vai melhorando".

É interessante notar que essas pessoas levavam vidas rurais em seus estados de origem. Em geral, enquanto solteiros, tocavam a lida diária no sítio e, quando já casados, possivelmente haviam recebido ou arrendado um exíguo pedaço de chão. Assim, o contato com a terra, as plantas, os animais não era uma novidade para essas pessoas. São problemas fundiários que, muitas vezes, provocam o êxodo em direção às cidades, como lembraram D. Ilma e D. Marieta, respectivamente:

E lá [Piauí] nem era terra nossa, era dos outros. A gente vivia no cabo de enxada cuidando do que não era nosso.

Aí, a gente veio para Brasília. Era melhor porque lá na Bahia a gente não tinha nada nosso. A gente podia trabalhar na terra do meu tio, mas a terra ia ser sempre dele.

Mas o que talvez lhes provocasse um desassossego ao chegar na Guariroba era a continuidade daquele "rural" ainda nesse espaço urbano, ou idealmente percebido como "urbano". Para reforçar este ponto: elas já haviam fugido uma vez da "poeira" ou do "sufoco", como disse acima D. Deusdete, e talvez os espantasse e esmorecesse reencontrá-lo nesse espaço da Guariroba, com a presença de cobras, mato e lama, mas também com a ausência de asfalto, ônibus, hospital, água encanada.

Outro tipo de dado apareceu em nossas conversas. Diferente do que Borges mostrou para o caso do Recanto das Emas, ali na Guariroba o morador não podia opinar sobre a distribuição feita pela SHIS. Na etnografia mencionada, uma das senhoras '“cismou' com Santa Maria e transferiu sua inscrição para o Recanto das Emas. No relato desse casal essa decisão toma as feições de uma escolha, uma espécie de idiossincrasia a que se permitiram diante de um contexto pleno de constrangimentos exteriores" (Borges, 2004:38). Ao passo que, no bairro por nós estudado na Ceilândia, ouvimos, por exemplo, que as "quadras" e os "conjuntos" foram organizados por ordem alfabética e é por isso que encontramos ruas em que todas as proprietárias originais eram "Marias", ou outra em que todos os nomes dos donos se iniciavam com a letra "H", por exemplo. D. Leila, por sua vez, lembrou que, ao ter acesso à sua casa, percebeu, em consulta aos vizinhos, que todas as chaves eram idênticas, com o potencial de abrir todas as portas da rua.

Estas características da Guariroba eram relatadas com desconfiança e, mais do que tudo, desencantamento, numa clara percepção de que era um bairro feito no "atacado", sem espaço para idiossincrasias ou moradias personalizadas. Diante de dados como estes, ficamos com a impressão de que a casa foi mais "ganhada" no sentido de dádiva, que não pode ser questionada, do que "comprada", já que foram pagas pelos moradores ao longo dos anos. "Ganhar" e "comprar" a casa da SHIS vão indicando feições de maior ou menor poder de decisão desses moradores em relação à experiência de viver e construir a história da Guariroba.

29 Ainda assim, pelo que entendemos, ir morar no "nada", como disse acima D. Miriam, só valia a pena para "sair do aluguel" ou deixar de "morar na casa dos outros": 5

Mas aí saiu a inscrição da SHIS que eu fiz. E eu ganhei essa casinha que tenho aqui. Era a coisa que eu mais queria no mundo, a minha casa. No começo, eu nem queria sair pra trabalhar. Queria ficar dentro de casa, curtindo a casa! A minha casa, só minha. Tenho vizinhos muito bons, muito bons mesmo. Gosto daqui que só. Tenho 
dois irmãos que ainda moram na Bahia, alguns sobrinhos, mas não volto pra lá mais. Meu lugar é aqui na Guariroba. (D. Dolores)

Quando chegamos, ficamos morando na casa dos outros. Foi sofrimento demais isso, meu deus. A gente não tinha condições de morar numa casa nossa. Ele [o marido] ganhava pouquinho. Então, fomos morar com os parentes dele, porque ele tinha gente pra cá. Mas foi muito sofrimento, eu com os meninos pequenos. Era muita humilhação. A gente tava ali morando de favor e eles jogavam isso na cara da gente. "Vai embora, aqui não é a sua casa", diziam assim para a gente toda hora. Batiam nos meus filhos, era só eles passarem assim, que eles pegavam a vassoura e batiam neles. Mandava a gente embora o tempo todo. Aí, finalmente, a gente conseguiu essa casa aqui. "Aqui é nosso", eu pensava. Eu fiquei feliz demais. Era tudo que eu queria, um canto nosso. Isso aqui, eu posso te dizer, é o meu palácio. É simples e tudo, mas é nosso, é um palácio para mim. (D. Inara)

Ah, minha filha é um aperto morar de aluguel. Conseguir essa casa aqui foi um presente. (D. Melinda)

30 Essas dificuldades todas, que dizem respeito à urbanização de uma nova cidade, mas também falam da frustração das expectativas em relação ao Estado (na figura da SHIS), é o que chamamos aqui de "tempo da falta". Mas, de forma concomitante, como mostraremos com mais vagar na seção seguinte, essas pessoas só conseguiram enfrentar esse "tempo da falta" porque um "tempo de bonança" despontava com força na figura da casa recebida, na propriedade do imóvel, no sorteio do nome pela SHIS. Como a esposa de Seu Geraldo lhe disse, acima: "Vamos ficar. Depois vai melhorando". Era importante apostar na transição de um tempo para o outro.

31 Ficar e ver melhorar, além de aposta, tem nas falas dessas pessoas outra acepção, meio implícita, que a longo prazo ajuda a positivar e a nuançar um pouco esse "tempo da falta". Ter visto a Guariroba, bem como a Ceilândia passarem de "mato" à "cidade" (na ideia acima mencionada de uma "urbanidade digna") é poder ser associado a esse primeiro tempo. Relatos que tão comumente encontramos em outras etnografias sobre a "falta de água", por exemplo, são provas de que essas pessoas testemunharam os idos tempos. Embora não tenhamos ouvido essas pessoas se definirem como "pioneiros" ou "fundadores", como em outros espaços do DF tem sido notado pelos pesquisadores (Patriota de Moura, 2010; Magalhães \& Brayner, 2001), parece que, com exemplos práticos, algo nesse mesmo sentido nos estava sendo comunicado, ou ao menos discretamente reivindicado. Se, naquele tempo, estar naquele espaço era um desafio à sobrevivência, no presente este mesmo quadro aparece como uma oportunidade de empoderamento narrativo.

Diante das perguntas, essas pessoas se localizavam na produção da história da Guariroba, da Ceilândia e também do DF como protagonistas ativos, tanto em termos de tempo quanto de espaço. "Eu vi aqui da soleira da porta de casa os caminhões do asfalto trabalharem", "Eu lembro quando começou a passar ônibus aqui na nossa rua", "Eu vi isso aqui virar cidade" - estas foram frases que escutamos com alguma frequência. Assim, não é corriqueiro que escolhessem nos contar suas histórias de vida a partir das trajetórias de sua família e também dos espaços por onde passaram. É o "tempo da falta" que realça e confere sentido ao "tempo da bonança", como se verá a seguir. Como percebeu Uchôa em sua pesquisa com mulheres idosas em Bambuí (MG): “parece ser mais na capacidade de superar eventos dolorosos, redefinir prioridades e integrar mudanças do que no alcance de uma meta preestabelecida que se fundamenta uma avaliação positiva" (2012:31). 


\section{O tempo da bonança: casas maiores, ascensão social e as redes vicinais}

33 Aos poucos o "tempo da falta" foi sendo suplantado, com muito esforço e planejamento dessas famílias, mas também através de políticas de urbanização. Poderíamos sugerir que o bairro foi se "consolidando", no sentido problematizado por Cavalcanti. Enquanto lembra os programas das últimas décadas nas favelas cariocas, como "eletrificação de favelas", "gari comunitário", "cada família um lote" e "favela-bairro", Mariana Cavalcanti também pondera sobre o conceito:

De um ponto de vista antropológico ou, mais precisamente, etnográfico, pensar a favela consolidada implica levar em consideração a historicidade da favela como forma social e espacial, ou melhor, pensar a consolidação de favelas como processo espaço-temporal, atravessado por relações de poder que se (re)produzem em diversas escalas. [...] Em suma, pensar a consolidação das favelas traz à tona a questão de como as espacialidades da consolidação urbanística e da "melhoria" para usar uma expressão cara aos agentes nela envolvidos - se choca, intersecta ou justapõe ao que é sabido ser o aspecto mais crucial da vida cotidiana em estruturas que conectam a favela - agora com o território do tráfico - a uma economia política no bojo do que se convém chamar de "criminalidade violenta" (cf. Machado da Silva, 2004); (Cavalcanti, 2009:71).

Assim, do ponto de vista dos urbanistas e estadistas e também das pessoas entrevistadas - todos eles tidos como "agentes envolvidos na consolidação urbanística e sua melhoria", como disse Cavalcanti - a Guariroba poderia ser considerada, nos dias de hoje, como um produto "consolidado" de bairro popular planejado. Nesse sentido, destacaremos abaixo três aspectos dos discursos que indicam a suplantação daquele "tempo da falta".

Mas, se atentarmos bem, as pessoas continuam a perceber que esse novo tempo, que aqui chamaremos provisoriamente de "tempo da bonança", pode ter relação mais estreita com suas experiências de ascensão social (no trabalho, na construção da casa e na descendência) e não serem necessariamente equivalentes, em termos de "consolidação", ao bairro ou à cidade como um todo. Assim, como Cavalcanti tenciona a naturalização do conceito urbano de "consolidação", ao trazer a justaposição de tantos outros fatores na favela por ela estudada (inclusive do tráfico de drogas), podemos perceber que "faltas" ainda são percebidas pelos guarirobenses em seu território, sobretudo quando comparam a cidade da Ceilândia com outras do DF, como Vicente Pires, Águas Claras ou o Plano Piloto, ou mesmo quando notam a diversidade dentro da Guariroba, com a valorização imobiliária e também moral dos espaços mais próximos ao metrô ou às escolas, aos hospitais e aos serviços.

Desta forma, com este comentário inicial, queremos manter os "tempos" aqui ficcionalizados por nós como realidades permeáveis, não encompassadoras de sentidos unívocos. No "tempo" que descrevemos a seguir há uma preponderância da ideia de "melhoria" em relação ao tempo discutido na seção anterior, mas sem pretensões absolutamente redentoras, nem de nossa parte, nem da parte das pessoas que temos conhecido na Guariroba. Os outros dois tempos que virão depois ajudarão a relativizar qualquer mitificação dessa bonança aqui descrita.

Vejamos três aspectos que permitem observar como o "tempo da falta" foi sendo deixado para trás: a nova casa, a expansão da família e os laços vicinais. No caso do crescimento gradual da Guariroba, vale lembrar que parece que "as narrativas se 
adensam quando se amplia o panorama da cidade, quando os percursos e os circuitos urbanos deixam os limites mais próximos da vizinhança" (Lins de Barros, 2006:25).

Primeiro, a casa "recebida da SHIS" foi sendo alterada, sempre em prol do bem viver, para melhor comportar as famílias que cresciam. Há também a clara demonstração de que a renda se incrementava aos poucos, gerando ao mesmo tempo mais estabilidade, conforto e enraizamento. Uma cena muito comum, quando passamos a frequentar o interior das casas, era a forma como as pessoas escolhiam nos explicar sobre como as casas haviam crescido para trás e para cima dentro do lote. Elas sempre se levantavam do sofá, posicionavam-se no limite entre a sala e a cozinha e diziam, com os braços esticados paralelos ao chão: "A casa vinha só até aqui. A partir dessa cozinha nova, para trás, não existia”. Em seguida, traçavam com linhas imaginárias, lembrando-se da época em que haviam recebido a "casa da SHIS" na década de 1970, como era a distribuição dos módicos cômodos, sempre descritos no diminutivo: "Aqui, tinha uma salinha, ali era o quartinho, ao lado a cozinha e um pequeno banheirinho". Constantes eram as menções à "casinha", ao "ovinho" (Seu Gabriel), "imprensadinha" (D. Susana).

D. Glória lembrou que "dormia tudo empilhado, um em cima do outro. Só assim para caber". o lugar de dormir parece ter sido o que mais exigiu organização, já que as famílias tendiam a ter filhos e agregados, mas contavam apenas com um dormitório. É daí que surge justamente a necessidade de expansão: "Nossa casa estava no contrapiso ainda. Tinha um quarto só e depois é que fizemos um puxado. Dormiam as moças no quarto com a gente e os rapazes, aqui na sala. Era bem apertado. Depois, com o puxado, melhorou um pouco" (D. Marta).

Segundo, não só as casas melhoraram, mas a descendência desses casais já reflete uma mudança significativa em termos de mobilidade social. Hoje em dia, poucos são os filhos que trabalham, já adultos, na construção civil ou no serviço doméstico. Em geral, encontramos funcionários concursados dos Correios, da Polícia, da Secretaria de Educação. Outros são funcionários de empresas privadas, como lojas de material de construção, concessionárias de carros, fábricas de leite etc. Encontramos jovens como vigilantes, frentistas, motoristas. Algumas mulheres são professoras, manicures em salões de beleza e, quando na limpeza, são funcionárias contratadas de empresas terceirizadas que atuam em hospitais ou escolas.

41 Essas ocupações indicam que os filhos desses migrantes conseguiram completar níveis básicos e intermediários de estudo e, por isso, lograram oportunidades menos braçais e custosas como as que seus pais tiveram que aceitar ao chegarem à Brasília para poder sustentar a família. O nível de escolaridade aumentou muito, já que vários dos idosos que conhecemos mal sabem ler e escrever, enquanto seus filhos, em número significativo, já têm curso superior ou, ao menos, cursos técnicos e o ensino médio concluído. Por conta dessa escolaridade mais elevada dos filhos, que muitos desses senhores entrevistados se comprazem em exibir, foi possível a eles deixarem a casas dos pais e morarem mais perto dos postos de trabalho.

Como terceiro ponto da passagem do tempo da falta ao da bonança, era possível notar o investimento relacional, os laços que esses entrevistados foram construindo na sua rua na Guariroba. Quando elas recontavam a experiência de viver ali por tantas décadas, era comum mencionarem seus vizinhos e a proximidade pacífica estabelecida com eles. D. Eulália, por exemplo, falou com muita clareza: "Eu moro aqui há 40 anos. E nunca tive um intrigado na vida. Nunca tive". A presença das boas relações sociais vicinais foi 
um importante contraponto à ausência da ambientação urbana à época em que ali chegaram:

Aqui não tinha asfalto, era tudo terra aí na frente. Tinha muita fossa por todo lado. Mas foi melhorando aos poucos. Os vizinhos daqui são ótimos. A D. Silvia, que mora três casas para lá, é maravilhosa. Só vendo, tenho que apresentar para vocês. Quando a gente mudou pra cá, nossos filhos tinham a mesma idade. Então, eles cresceram tudo apegado demais. A D. Silvia já tem idade também, mas é mais nova que eu. Quando eu saía para trabalhar, tinha que deixar eles para trás, ela ficava de olho, ajudava. Naquela época, não tinha portão aqui, não tinha muro. A gente entrava na casa um do outro, era mais fácil. (D. Miriam)

A transformação física das casas, a ascensão social da família e os fortes laços locais empreendidos demonstram como, na altura da vida em que atingem seus 60 ou 70 anos, essas mulheres e esses homens conseguiram suplantar o tempo da falta dos idos de 1960 e 1970. Estão no "tempo da bonança", em que tudo está mais bem construído, baseado em desejos, escolhas e investimentos que essas pessoas, suas comunidades e os governos fizeram nesse decorrer. Algumas delas aprimoraram tanto sua estabilidade que, do tempo em que "viviam de aluguel", agora podem "viver do aluguel".

Eu trabalhei a vida toda com venda de balinhas. Mas pensava assim: "Como posso achar uma atividade que me dê sustento sem que eu tenha que ficar de sol a sol vendendo balinhas?". Aí eu pensei nos aluguéis. Eu não preciso sair daqui e o dinheiro entra para mim. Foi uma forma de garantir a minha velhice com tranquilidade. (D. Melinda)

Da planta original da SHIS, essa senhora mineira ergueu uma laje, construiu no piso superior três pequenos apartamentos que aluga para pessoas solteiras ou casais sem filhos. E pôde ficar morando no andar térreo .

É bom pontuar que, ainda que reproduzam o termo "bairro", vale cuidado nesse uso. Os cientistas sociais portugueses Cordeiro e Costa sugerem como pouco produtiva as concepções empiristas e naturalistas do termo "bairro", "assumida[s] como noção autoevidente enquanto designação de uma unidade urbana não problemática em si própria - ou, na tradução teórico-metodológica tantas vezes presente nas ciências sociais, tomada como 'unidade de análise' reificada e apriorística" (1999:72). Eles lembram que, em geral, as fronteiras de um bairro,

revelam-se ambíguas, plásticas, contextuais e estratégicas, dependentes de quem se pronuncia e das situações relacionais em que está envolvido. Em particular, as representações simbólicas locais acerca destes bairros como entidades colectivas de referência e pertença constituem-se mais por núcleos de enraizamento identitário e demarcações sociais em face de terceiros [...] do que por delimitações cognitivas de contornos precisos, como é habitual nas definições administrativas ou cartográficas (1999:72-73).

Durante nossa convivência na Guariroba, era comum certa imprecisão de seus contornos. Mesmo que todos se referissem à localidade como "Guariroba" e, na maior parte dos discursos a Guariroba fosse a indicação que norteasse as memórias, sempre que mencionavam o local, ouvíamos alusões ao pertencimento: "minha rua está aqui na Guariroba", "essa daí mora no final da Guariroba", "essa quadra já não é Guariroba" etc. Embora houvesse algum consenso sobre o que era, na prática, o bairro, os limites espaciais eram ligeiramente maleáveis, como ensinam Cordeiro e Costa, desenhados conforme nosso conhecimento sobre o "bairro", mas também de acordo com as intenções de comunicação estratégica de nossos interlocutores. 
47 Assim, notamos que pertencer à história da criação da Guariroba como bairro de "casas da SHIS" é associar-se à uma Ceilândia, digamos, organizada ou mesmo "consolidada" em contraponto aos "barracos da Ceilândia Norte", ainda na década de 1970, ou àquilo que identificam nos dias atuais como porções socialmente desvalorizadas, como o "P. Sul" ou os "condomínios populares", como o Sol Nascente ou o Pôr do Sol (Patriota de Moura, 2010). Ter "recebido uma casa da SHIS" e ter conseguido incrementá-la com os próprios recursos são dois eventos distintivos para esses interlocutores. Percebemos também que havia algumas pessoas que aventavam vender sua casa na Guariroba, muito valorizada por estar próxima da linha do metrô, para comprar uma casa em um bairro ou em uma cidade mais periférica. A ideia era de que a diferença entre os valores das duas casas poderia se converter em um recurso para subsidiar a aposentadoria, sobretudo no caso dos senhores que trabalharam como autônomos a vida toda.

Além disso, essa maleabilidade dos limites da "Guariroba" indica outro dado correlato relevante. Se nos concentramos em um "bairro",

não significa que estes contextos locais constituam guetos sociais, parados no tempo e fechados ao exterior. Pelo contrário, [nestes] contextos, nos quais ocorre a referida densificação de laços sociais e formas simbólicas, não só são atravessados por significativos processos de mudança, como se constituem enquanto cenários de múltiplas intersecções, de carácter estrutural, institucional, relacional e cultural (Cordeiro \& Costa, 1999:75, grifos nossos).

Neste artigo, nossa intenção tem sido justamente demonstrar as mudanças ao longo do tempo. Se, por um lado, precisamos atentar para as acepções vigentes de "cidade" e "bairro", por outro, também devemos manter em perspectiva a ideia de "consolidação", como Cavalcanti sugeriu. Aventamos a possibilidade de pensar não só em um bairro consolidado de forma relativa, já que nuances de mais ou menos "melhorias" eram claramente percebidas pelas pessoas, mas talvez até em uma saúde consolidada. Nesse "tempo da bonança", além de casas e famílias constituídas, as pessoas mencionavam como tinham "saúde", força para trabalhar, comida farta na mesa, reuniões animadas aos domingos. Depois de alguma carestia nas regiões de origem no Nordeste ou em Minas Gerais, encontravam no DF e na Guariroba possibilidades de crescimento. Mas como Cordeiro e Costa disseram há pouco, os bairros - e nós acrescentamos, os corpos e suas histórias - não podem ser vistos como parados no tempo. A cada "novo tempo", como temos retoricamente designado neste artigo, desafios urbanos são relacionados a desafios no âmbito da saúde, como se verá na seção seguinte.

\section{Um novo e inesperado "tempo da falta", uma nova tentativa de "tempo de bonança"}

Observamos que é justamente no que acaba de ser descrito como o "tempo da bonança" que as doenças crônicas, como a hipertensão arterial e a diabetes mellitus - para ficarmos nos exemplos epidemiologicamente mais significativos - surgem e fazem instaurar um novo "tempo da falta". Os corpos apresentam-se menos confiáveis, menos resilientes. Eles, que por tanto tempo sustentaram as lidas diárias duríssimas, agora se apresentam falíveis.

Antes eu era muito saudável, não procurava o médico. (D. Nicole)

Olha, tem 30 anos que eu perdi meu marido. Eu tive que ir trabalhar para sustentar meus cinco filhos. Eu tive sete, mas dois morreram pequenos. Eu trabalhava muito, mas eu não sentia nada, nada. Eu trabalhei tanto tempo e nunca tive nada. Tinha 
era uma saúde muito boa. Tinha força, fazia de tudo. Mas aí, foi aposentar, deu um tempinho e acusou a doença. (D. Miriam)

51 Em várias de nossas conversas com essas senhoras e esses senhores há depoimentos que sincronizam o início da "pressão alta" ou do "açúcar no sangue" com a aposentadoria, a viuvez, a menopausa, a morte de um filho adulto ou dos progenitores nos estados de origem. É no início da velhice que as doenças chegam, nos explicaram.

Eles diziam faltar coragem, força, disposição, apetite, independência. Assim, sugerimos que haja um novo tempo da falta. A comida que sempre foi elaborada por essas matriarcas não serve mais. É preciso "comer insosso" ou, ao menos, em "panelas separadas", como nos disseram. Em uma panela se produz a "comida temperada", enquanto na outra, o "entulho", como disse D. Renata, já que nem sal nem condimentos são recomendados. Os almoços de domingo não são tão elaborados e, por conta disso, não conseguem mais atrair aquela visita semanal dos filhos que moram em outras quadras da Guariroba, da Ceilândia ou mesmo do DF.

53 Quando perguntamos à D. Miriam se era ela quem cozinhava na casa, ela disse: "Ih, cozinhava, hoje, faço mais nada, não. Fazer para quê? Não posso comer". Ao ouvir isso, sua filha Nara, que estava na cozinha preparando o almoço, comentou: "Ela gostava mesmo, gente, era de doce. Doce de mamão, né, mãe? E gostava de canjica, de feijoada, buchada de carneiro, dobradinha, frango". Atenta, D. Miriam ouviu a filha, assentiu e completou:

É mesmo, vinha todo mundo pra cá no domingo, a gente fazia aquela comidaiada gostosa, boa que só. Hoje, não tem graça mais. Não pode comer nada. Para que vir pra cá, então, né? É comida veia, não é gostoso nem nada. Já pensou refogar as coisas em óleo de girassol? Bom mesmo é no toucinho. Mas não posso mais. Não tenho gosto mais de nada, não. De vez em quando, como um frango assado, assim. Mas a gente perde o gosto para comer.

54 Para além da comensalidade cotidiana, as festas, cuja frequência segue proporcional à densidade dos laços sociais, não podem ser desfrutadas plenamente, sobretudo quando não se conta com o autocontrole necessário para evitar os brigadeiros das festas infantis, ou os churrascos das festas de adultos. A sociabilidade que permite, nessa altura da vida, fartura de carne e cerveja, se torna arriscada. Um novo corpo, frágil e suscetível, se apresenta, desorganizando toda uma rotina que foi estabelecida com esforço e trabalho. O tempo da bonança, conquistado com dificuldade e que começou a ser aproveitado mais perto da velhice, é percorrido por um novo e imprevisto tempo: o da falta de saúde.

55 Além da própria doença, o que estamos sugerindo é que também seus tratamentos geram problemas. Era muito comum as pessoas reclamarem das novas prescrições dietéticas. Deixar de comer o que se aprecia, sobretudo quando são alimentos relacionados às origens regionais, era tido como enorme sacrifício. Mas também os medicamentos produziam novas realidades desafiadoras. No caso masculino, os antidiabéticos, por exemplo, são notórios responsáveis pela disfunção erétil. No caso feminino, provocam efeitos diuréticos. Já sobre os anti-hipertensivos era comum ouvir relatos de tosse incessante. Estas são adversidades que comprometem a convivência social, contribuindo muitas vezes para o autoisolamento e até para quadros depressivos. Aqui se percebem indicativos de perda de intimidade sexual, de rotinas públicas (torna-se difícil sair de casa, já que não há muitos banheiros disponíveis), de participação em ambientes que exigem silêncio (com a tosse, é penoso ir a igrejas ou cultos, cursos, casas com recém-nascidos, por exemplo). 
56 Assim, aventamos que tanto no primeiro "tempo da falta", quando na década de 1970 mudaram para a casa nova na Guariroba, quanto nesse segundo "tempo da falta", já no século XXI, em que se instalam as experiências com as doenças que não têm cura, ou por eles chamadas de "doenças compridas", haja um enfrentamento similar das situações de imprevisibilidade. Depois de décadas de labuta, o tempo da velhice e da aposentadoria não poderão ser desfrutados sem uma nova forma de belicismo, expressado na "luta contra a diabetes" ou na "luta contra a pressão alta" (similar à ideia de "luta pela casa", muito usada no início da Guariroba). Esse novo tempo da falta exige que um novo tempo da bonança seja conquistado, com o imperativo de uma nova socialização e disciplina corporal para cuidar dessas doenças. No momento da vida em que essas pessoas atingiram, por mérito e sorte, uma estabilidade social e financeira muito maior do que seus antepassados lograram alcançar nas regiões de origem, surge a necessidade de voltar ao regramento, ao comedimento, à adaptação. Quando renda, casa e família estão mais estabilizadas e se poderia desfrutar de menos frugalidade, rotinas de dieta alimentar e medicamentos são prescritos pelos profissionais da saúde para controlar o insistente "18 por 10" (de pressão) ou o "200" (de glicose), como nos diziam.

Uma diferença, no entanto, é que hoje esse novo tempo da falta é enfrentado com alguma desvantagem, já que esses sexa e septuagenários contam com desafios diferentes daqueles da época em que vieram desbravar a Guariroba. Há menos vitalidade, os corpos estão muito mais cansados, sobretudo pelo tipo de trabalho que exerceram a vida toda. Há menos companhia, pois muitas dessas pessoas são viúvas, há cônjuges acometidos por AVCs incapacitantes (sem mobilidade, sem fala e com muita exigência por cuidados), os filhos e netos que ascenderam foram morar em outras cidades, e vários de seus vizinhos faleceram ou mudaram dali, em busca de bairros ou cidades mais valorizados no DF. Essa nova configuração familiar e vicinal apresenta outro quadro para o cuidado das doenças crônicas.

Não se pode perder de vista que este novo tempo da falta surge depois daquele primeiro tempo da bonança. Isto quer dizer que, diferente do primeiro tempo da falta, ainda nos anos 1960, este segundo pode contar com alguns acúmulos, como um patrimônio um pouco mais estável, filhos adultos que em geral também geram renda e algum conforto, a cidade e o bairro mais estruturados (inclusive com mais equipamentos de saúde e lazer para idosos, por exemplo) e conhecimento sobre a própria história pessoal e a dinâmica corporal. Além disso, embora essas pessoas se referissem aos filhos como D. Marieta uma vez fez - "São todos casados, tudo tem a vida deles" - também foi possível notar o apoio dos filhos adultos e dos netos adolescentes. Viver em outras casas e cidades não necessariamente comprometia o contato e a presença dessa prole.

Os três filhos de D. Marieta, por exemplo, sempre ofereciam para levar o pai adoentado por um AVC para passar o final de semana em suas casas, embora ele preferisse ficar sob os cuidados da esposa. D. Miriam, e recebia de um filho que era policial plano de saúde, medicamentos e "sacoladas" semanais de verduras e frutas. Sua filha, embora também vivendo em outra cidade, vinha limpar sua casa e fazer-lhe comida algumas vezes na semana. No dia em que fomos fazer uma filmagem na casa de D. Mariana para outro projeto em curso, sua filha tinha vindo especialmente para maquiá-la. Era comum também, durante nossas visitas, notar que a anfitriã recebia vários telefonemas dos filhos, checando como caminhava o seu dia. Estes são elementos que ajudam a enfrentar a nova falta gerada pelos diagnósticos crônicos e também a colocar em perspectiva 
cenários mais lúgubres em que as "doenças compridas" são enfrentadas em cenários de extremada pobreza (o que não foi encontrado nesse universo pesquisado).

Ainda assim o que percebemos é uma atmosfera de desilusão. Parece que esperavam que, uma vez alcançado o tempo da bonança - com a casa própria e ampliada, a aposentadoria no bolso e tempo livre - ele perduraria até o fim da vida. Mas são tomados de assalto por um novo e inesperado tempo da falta, como Costa percebeu na década de 1970 entre trabalhadores de Planaltina, em que a saúde era sobretudo "riqueza de pobre" (1978). O adoecer desaba sobre nossos entrevistados como um processo de empobrecimento, como uma nova vulnerabilidade. Toda essa retrospectiva, que retoma a chegada dessas pessoas ao DF, talvez indique que as distintas temporalidades possam nos ajudar a entender o desafio de receber um diagnóstico de cronicidade e cuidar dele. Nossa intenção neste artigo é experimentar a rentabilidade de se espelharem topografias, cronologias e cronicidade, isto é, observar o quanto dialogam, primeiro, as topografias na forma de espaços de referência (entre o Nordeste e o DF); segundo, as cronologias como os tempos ao longo dos quais esses espaços mudam (os anos 1960/1970 e o século XXI); por fim, a cronicidade vivenciada pelos corpos que, por sua vez, perpassam diferentes topos e cronos, já que se foi jovem num corpo saudável e depois se envelheceu e o corpo se apresentou adoentado.

61 A palavra que mais ouvimos no cuidado com essas doenças crônicas, tanto nos espaços domésticos quanto nos institucionais, é "controle". ${ }^{6}$ A comida, os medicamentos, as visitas aos hospitais e às farmácias, a prática de exercícios físicos, as aferições dos índices corporais, tudo precisa ser submetido a um regime estrito de controle. Agora são calorias, miligramas de mercúrio, unidades de açúcar, horários das refeições, dias da prática esportiva, semanas de intervalo entre as consultas, ou seja, números e frações a regrarem tanto as ações quanto as sensações corporais e as relações sociais dessas pessoas. $O$ controle é a principal estratégia para enfrentar a pressão ou a glicose "descontrolada", "destrambelhada", como costumavam chamar. o controle é a mais recorrente iniciativa para lidar com as doenças incuráveis e, assim, conseguir suplantar esse novo tempo da falta no sentido de transformá-lo num novo tempo de bonança, mesmo que relativo e restritivo. Esse novo saber - o "controle" - não era incrementado apenas pelos adoecidos, mas também pelos seus cuidadores. As injeções de insulina eram dadas em D. Leila por sua filha, que fora treinada pela auxiliar de enfermagem do Centro de Saúde da redondeza. A filha de D. Inara foi quem a presenteou com um esfigmomanômetro.

É por isso, talvez, que tenhamos ouvido tanta gente falar que "não tem problema de glicose nem de pressão porque está tudo controlado". o objetivo cotidiano e coletivo em termos da família, mas também das equipes de saúde, por exemplo - era alcançar um estado "controlado". Os esforços eram para reconquistar um novo tempo da bonança, isto é, em que os índices corporais e mais do que tudo o bem-estar pudessem se "normalizar" de novo. O imperativo de controlar os problemas de saúde e, consequentemente, os corpos parecia moral - assim como foi também vencer nos anos 1970 a migração, o cerrado, o inicial e desolador bairro. Era uma questão de honra sair da própria terra e sobreviver na capital federal, e da mesma forma o é controlar a pressão e o açúcar no sangue, mantendo-se, respectivamente, um " 12 por 8" ou um "abaixo de 100". Não era fortuito o fato de essas pessoas recorrentemente comentarem sobre a forma com que um parente ou um vizinho cuidava de suas "doenças compridas", sempre aquém do que o narrador fazia para tratar a sua saúde. As 
comparações e as autocongratulações reforçam o peso moral de saber sobre essas doenças crônicas e cuidar delas.

Eram dois tempos da falta - da novíssima Guariroba e também do corpo envelhecido sendo heroicamente domados por dois tempos da bonança - o controle das cobras, da falta de água, do mato no bairro que nascia, e também das doenças crônicas, na atualidade. Há uma alternância entre esses tempos, um tempo da falta nos anos 1960-1970, depois um tempo da bonança, quando a casa da SHIS e a estabilidade financeira são construídas pela família nos anos seguintes. Há um novo tempo da falta, já neste século XXI, com o despontar das doenças crônicas. Hoje em dia, nas conversas com essas pessoas, percebemos como tentam instaurar um novo tempo da bonança, do controle, do regramento, da disciplina. "Fechar a boca", "tomar os venenos [medicamentos]", "fazer a física [ginástica]" e, sobretudo, "evitar as preocupações" eram as principais medidas de autocuidado para segurar a pressão ou a glicose. Mas, diferente da comida, dos remédios e dos exercícios físicos que são em geral consumidos individualmente, as "preocupações" apresentam-se como um enorme desafio a ser manejado, já que pressupõem contextos relacionais e, também por isso, menos previsíveis (Fleischer, 2013).

Ainda assim, se a posse do espaço na Guariroba se garantiu com as sucessivas benfeitorias ali investidas, percebemos que o domínio da experiência do adoecimento crônico também traz a decisão de enfrentá-lo. Isto significa, num primeiro momento, aprender a identificar a alteração indesejada dos índices corporais e depois a revertê-la ao parâmetro do "seu normal", o que acontece não só em função da dieta e dos medicamentos, mas também pela participação em espaços que servem para encaminhar esses senhores na direção do autocuidado e para compensar de alguma forma as "preocupações". Ir aos forrós da terceira idade, fazer ginástica em vários Centros de Saúde, participar das viagens organizadas para balneários termais no estado e estar com frequência nas igrejas locais eram atividades que ajudavam na passagem de "ser controlado pela doença" para "controlar a doença".

É bom notar que esses são espaços onde facilmente se encontram pessoas convivendo com as mesmas doenças, depurando os mesmos saberes do "controle" e, por isso, aptas a ajudar com dicas de posologias alopáticas ou fitoterápicas ou a atender alguém que passa mal durante a viagem ou num baile matinê, por exemplo. Assim, percebemos que transpor o tempo da falta para o da bonança poderia ser alcançado quando o ator passasse de passivo a ativo. Em vez de resignar-se com uma "casinha", partiu-se para expandi-la e rebuscá-la. Em vez de se deixar derrubar pelos problemas de pressão, decide-se encontrar outros "hipertensos" com quem conviver, trocar e aprender a controlar-se. Ouvimos de Seu Fernando que é "você quem tem que controlar ela, não ela controlar você". E D. Renata e D. Fátima nos explicaram que "ela não é 'minha', eu não falo 'minha"', referindo-se ambas à diabetes. Os momentos da falta talvez sejam tempos de pouca autonomia, enquanto os da bonança anunciam processos de apropriação dos caminhos que se deseja seguir.

\section{Considerações finais}

Estes quatro tempos consistem apenas em uma alegoria que utilizamos para tentar entender as mudanças e os esforços adaptativos que nossos interlocutores têm empreendido nos últimos 50 anos no Distrito Federal. Eles não nos narraram suas 
histórias por meio desses "tempos", mas a alternância entre experiências de desafios e de plenitude nos chamaram a atenção. No fundo, nossos esforços são no sentido de entender as doenças crônicas que são enfrentadas hoje em dia sem perder de vista a perspectiva diacrônica dessas vidas generosamente compartilhadas conosco. Acreditamos que há ainda muito por pensar sobre a ideia de "cronicidade", este termo complexo, mas naturalizado nos espaços biomédicos. Aqui, nosso intuito foi trazer um aporte da Antropologia, que valoriza tanto as biografias quanto os contextos sociais, para inferir algumas análises sobre esses moradores da Guariroba em meio à sua convivência cotidiana com a hipertensão e a diabetes.

Assim, pensamos que esses relatos em primeira pessoa podem nos ajudar a entender os cenários em que essas doenças são recebidas e cuidadas. Não é possível, nem muito produtivo, refletir sobre o adoecimento - sobretudo em caso de longa duração somente pelo viés fisiológico ou sincrônico. As doenças são anunciadas nos consultórios, mas são levadas para casa, comentadas pelas vizinhanças, tratadas no calor dos acontecimentos. E é impossível pensar em cuidar de pessoas com 60,70 ou 80 anos de idade sem considerar suas histórias de vida como migrantes para a capital federal. A densidade biográfica que carregam todos os dias e para todos os lugares aonde vão precisa ser levada em conta quando as equipes profissionais examinarem, prescreverem e aconselharem essas pessoas em seu convívio com a cronicidade.

No caso, os projetos de vida, que vinham traçados com aspectos de esperança e renovação com a chegada da aposentadoria, por exemplo, são interrompidos, ou ao menos reorganizados em função do surgimento das doenças tidas como "compridas" e de cuidado constante.

Embora haja uma ideia difundida socialmente de que não cabe aos velhos terem planos para o futuro, mostro em trabalhos anteriores que a velhice não impede a elaboração de projetos de vida (Lins de Barros, 2003). Estes são construídos no presente e pressupõem que o indivíduo tenha percepção de sua trajetória ou biografia (Lins de Barros, 2006:22).

É a percepção que essas pessoas guardam de sua trajetória passada, como lembra Lins de Barros, que permite planejamentos para o futuro. $O$ que tentamos mostrar é que as doenças interrompem, mais ou menos permanentemente, esses projetos, mas que com um novo tempo da bonança, sobretudo com o aprendizado do manejo do "controle" da doença, é possível reinventar essa etapa da velhice. Na verdade, quando ouvimos os relatos sobre o presente e o passado, sobre as cidades de origem, bem como sobre Taguatinga, Ceilândia e Guariroba, percebemos que a reinvenção não é uma novidade nessas biografias, mas uma nova reação diante de desafios expressivos. Ao enfrentarem os problemas de pressão e diabetes, não será a primeira vez que se depararão com agudas demandas por readaptação.

Falar da falta de urbanidade e também de saúde, falar das iniciativas para "domar" o mato na década de 1970 e da pressão descontrolada no século XXI é comunicar, em alguma medida, uma narrativa heroica de sucesso. Estas foram as pessoas responsáveis, segundo Norbert Elias, por "civilizar" aquele espaço e, em tempos mais recentes, "civilizar" o próprio corpo adoecido. Nas benfeitorias feitas nas casas, com suas lajes, expansões, portões e garagens, e também nos corpos, com seus glicosímetros, medicamentos e "alimentação saudável", é que notamos os esforços de comunicar a posse do espaço e do próprio corpo. Os dois tempos da bonança são também tempos da autonomia construída e conquistada, à qual não chegaram gratuitamente e sem 
esforços. Por isso, talvez, percebamos tantos senhores e senhoras em franco conflito com os filhos e netos para que deixem de regrar seus índices corporais, o sedentarismo ou o tipo de alimento ingerido. É um esforço para manter a autonomia, semelhante àquela que foi necessária para ficar na "casinha" tão modesta, na rua de barro e lama, no bairro sem escola ou hospital.

71 Assim como a Ceilândia foi ganhando status de "cidade" ou "região administrativa", que só a maturidade parece conferir, sugerimos, num efeito paralelo, que esses interlocutores também precisam barganhar os sentidos de uma velhice autônoma. Aprender a perceber quando uma glicose alta necessita de intervenção, descobrir qual é o melhor posto de saúde, em que horários há forrós para idosos são táticas para que cada um deles seja reconhecido como autor de sua própria história. Cuidar do próprio corpo e manter controladas, de alguma maneira, as "doenças compridas" são garantias de uma passagem eficiente da falta (de saúde) à bonança (também de saúde).

As narrativas aqui reunidas, que falam de experiências de doenças, também nos remetem a como essas pessoas percebem os diferentes tempos e espaços em que viveram. Mais do que isso, ao narrarem sobre sua trajetória da vida até os atuais quadros de cronicidade, também estão nos falando de cronologias e topografias da juventude à velhice, dos estados de Piauí, Paraíba e Minas Gerais até Taguatinga, Ceilândia Norte e Guariroba, no Distrito Federal. Patriota de Moura lembra que "o espírito pioneiro, como uma ação que transforma o cerrado, a lama e a poeira em uma 'cidade', permite a percepção da cidade como uma composição de relações" (2011:524, grifos nossos). A autora nos ajuda a entender que essas senhoras e senhores estão nos revelando as relações sociais - nas famílias de origem e nas que criaram no DF, nas vizinhanças diversas que tiveram, nos vários postos de trabalho, nos serviços de saúde e na cidade em geral - que foram empreendidas - e ainda o são - para construir um bairro, uma família e um corpo.

Aqui, intentamos mostrar como também o cuidado com a saúde e as experiências como adoecidos são dimensões do urbano. Por fim, aprendemos que fazer o espaço e contá-lo ao longo do tempo é também fazer-se e perceber-se neste ato de contar.

\#Notes

1.

3. 4.5.6.

\section{BIBLIOGRAFIA}

BONDUKI, Nabil Georges. 1994. "Origens da habitação social no Brasil”. Análise Social, XXIX (127): 711-732.

BORGES, Antonádia. 2004. Tempo de Brasilia: etnografando lugares-eventos da política. Rio de Janeiro: Relume Dumará. 
CAVALCANTI, Mariana. 2009. "Do Barraco à Casa: tempo, espaço e valor(es) em uma favela consolidada”. Revista Brasileira de Ciências Sociais, 24:69-80.

CORDEIRO, Graça Índias \& COSTA, António Firmino da. 1999. "Bairros: Contexto e intersecção". In:Gilberto Velho (org.). Antropologia Urbana. Cultura e sociedade no Brasil e em Portugal. Rio de Janeiro: Jorge Zahar. pp. 58-79.

COSTA, Ana Maria. 1978. Riqueza de Pobre: um estudo em antropologia da saúde. Dissertação de Mestrado em Antropologia, Universidade de Brasília.

FLEISCHER, Soraya. 2013. "O grupo da pressão: Notas sobre as lógicas do 'controle' de doenças de longa duração na Guariroba, Ceilândia/DF”. Amazônica, 5(2): no prelo.

LINS DE BARROS, Myriam Moraes. 2006. “Gênero, cidade e geração: perspectivas femininas”. In: Myriam Lins de Barros (org.). Família e gerações. Rio de Janeiro: FGV Editora. pp. 17-37.

1999. "A cidade dos velhos". In: Gilberto Velho (org.). Antropologia Urbana. Cultura e sociedade no Brasil e em Portugal. Rio de Janeiro: Jorge Zahar. pp. 43-57.

MAGALHÃES, Nancy Alessio\& BRAYNER, Natália. 2001. “Impactos da História de Brasília na (re)criação de identidades e direitos de moradores da Vila Planalto". In: André Ramos et al. (orgs.). Contar história, fazer história. História, cultura e memória. Brasília: Paralelo 15. pp. 181-189.

PATRIOTA DE MOURA, Cristina. 2010. “'Condomínios' no DF: clubes, favelas ou cidades?”. In: Aldo Paviani et al. (orgs.). Brasilia 50 anos: da capital à metrópole. Brasília: Editora da Universidade de Brasília. pp. 281-307.

2011. "Pioneers and Entrepreneurs: bio/ethnographic notes towards an anthropology of urban growth". Vibrant, 8:502-528.

RESENDE, M.L.S. 1985. Ceilândia em movimento. Dissertação de Mestrado em Sociologia, Departamento de Sociologia da Universidade de Brasília.

RIBEIRO, Gustavo Lins. 2004. O capital da esperança: a experiência dos trabalhadores na construção de Brasília. Brasília: Ed. UnB.

SARTI, Cynthia Andersen. 2003. A família como espelho: um estudo sobre a moral dos pobres. São Paulo: Cortez.

UCHOA, Elizabeth;FIRMO, Josélia O.A. \& LIMA-COSTA, Maria Fernanda F. de. "Envelhecimento e Saúde: experiência e construção cultural". In: M.C.S. Minayo \& C.E.A. Coimbra Junior (orgs.). Antropologia, saúde e envelhecimento. Rio de Janeiro: Editora Fiocruz. pp. 25-36.

\section{NOTAS}

1. Este artigo é produto do projeto de pesquisa "Como é conviver com a hipertensão arterial e a diabetes mellitus na Ceilândia? Aportes de uma Antropologia da cronicidade". A primeira autora é coordenadora do projeto e contou em 2012 e 2013 com a valiosa participação de três graduandos bolsistas de iniciação científica: Polliana Machado, Monique Batista e Hugo Cardoso. Aproveitamos para agradecer também às pessoas e às famílias que têm se disposto a nos receber para um dedo de prosa sobre temas tão corriqueiros para eles. Somos gratas também ao Centro de Saúde do bairro, ao Decanato de Ensino e Graduação, ao Decanato de Assuntos Comunitários e ao Departamento de Antropologia da Universidade de Brasília, que nos têm apoiado, entre outras coisas, com bolsas de pesquisa. Por fim, este texto se beneficia dos comentários generosamente oferecidos por Cristina Patriota de Moura, Christine Alencar Chaves e Larissa Polejack. 
2. A mesma autora lembra, contudo, que a Ceilândia "também testemunhou, após sua implementação, sucessivas ocupações irregulares, ora denominadas como 'invasões', 'favelas"' (Paviani, 1991 apud Moura, 2010:291), ou até mesmo "condomínios".

3. Também nesta pesquisa tivemos acesso aos prontuários dos pacientes que têm diagnósticos de hipertensão arterial sistêmica e diabetes mellitus e que participam das atividades costumeiras deste Centro de Saúde.

4. A "Sociedade de Habitação de Interesse Social" (SHIS), um dos primeiros órgãos de execução da política habitacional do Distrito Federal, ainda nos anos 1970 e 1980, disponibilizou a preços subsidiados, casas e lotes para famílias de baixa renda que haviam chegado à cidade. Como Borges mostrou em relação ao Recanto das Emas, "o recebimento do lote dependia e depende - ao menos em tese - da colocação obtida por quem pleiteia esse presente do governo numa espécie de lista dos merecedores" (2004:24). Em sua pesquisa, a autora descreveu os itens necessários para se alçar às melhores posições nessa lista de merecedores, como, por exemplo, a idade do candidato, o tempo de função no trabalho, o salário, número de dependentes, membro familiar com deficiência e, sobretudo o "tempo de [residência em] Brasília". No caso dessas pessoas que contatamos, foi mencionado que, para "ganhar" a casa da Guariroba, era preciso não ser desempregado, ter família, ter uma renda nem muito alta (mas que pudesse, em tese, pagar pela compra), nem muito baixa (que não conseguisse honrar as prestações do imóvel), garantir que se viveria na casa (em vez de sublocá-la) e, mais interessante, não ter se envolvido em problemas com a justiça, como "ter matado alguém", como algumas pessoas lembraram. A nosso ver, o "tempo de Brasília" fazia pouco sentido àquela época, já que todos, inclusive os dirigentes dos órgãos habitacionais, eram recém-chegados à capital. Parece que provar um valor moral - ser trabalhador, ser "de família" e ser idôneo - foi mais valorizado no caso da distribuição das casas na Guariroba.

5. É interessante notar que, mesmo em tempos mais recentes, exatamente este par de motivos é citado pelos jovens para deixarem casas na Guariroba e outros bairros da Ceilândia em busca de suas "casas próprias" ou, ao menos, seu "pedaço de chão". Nesses novos espaços estão dispostos a enfrentar limitações urbanísticas idênticas àquelas que nos foram relatadas. Entrevistado por Moura, uma das lideranças do Condomínio Sol Nascente, bairro bastante recente na Ceilândia, diz: "A grande maioria aqui ou morava de aluguel ou morava nos fundos da casa da sogra. Eu não sei o que é pior [...], mas temos essa realidade. Com todas as dificuldades que nós temos, a falta de energia, as más condições das nossas vias, somos felizes" (2010:293-294). Desejo de formação de um novo núcleo doméstico parece informar as decisões corajosas desses jovens de hoje e de outrora (Sarti, 2003).

6. Para uma discussão mais aprofundada sobre a categoria, ver Fleischer (2013).

\section{RESUMOS}

Nesse artigo, dados etnográficos sobre a convivência com a diabetes mellitus e a hipertensão arterial sistêmica pretendem dialogar com dados referentes às mudanças urbanas na cidade da Ceilândia/DF. As narrativas comunicam experiências de doenças e também sobre os diferentes tempos e espaços vividos por um conjunto de senhores e senhoras, hoje com 60 ou 70 anos de idade, que migraram para a região no início da construção da capital. Utilizando uma alegoria "tempos de falta" e "tempos de bonança" - pretendemos retratar as mudanças e os desafios que 
essas pessoas enfrentaram para construir suas famílias, o bairro da Guariroba na Ceilândia e também os corpos envelhecidos e adoentados.

In this article, ethnographic data about living with diabetes mellitus and systemic high blood pressure dialogue with data referring to urban changes in the city of Ceilândia/DF [Brazil]. Narratives relate the experience with these diseases over time and space of a group of men and women, in their 60s and 70s, who migrated to this locality when Brazil's national capital [Brasília] was being built (in the 1960s and early 1970s). Using the allegory - "times of shortage" and "times of bonanza" - we hope to portray the changes and challenges that these people faced as they attempted to organize their families in the Guariroba neighborhood in Ceilândia as well as coping with their aging and sick bodies.

ÍNDICE

Keywords: long-term diseases, Ceilândia, urban transformation

Palavras-chave: doenças de longa duração, Ceilândia, transformações urbanas

\section{AUTORES}

SORAYA FLEISCHER

UnB Soraya Fleischer é professora do Departamento de Antropologia da UnB. Pesquisa sobre “doenças compridas", isto é, doenças que não têm cura e exigem convivência e cuidado continuados. Contato: fleischer.soraya@gmail.com

\section{MONIQUE BATISTA}

UnB Monique Batista é graduanda em Ciências Sociais pela Universidade de Brasília. Tem pesquisado na Guariroba/Ceilândia/DF a convivência com doenças de longa duração e mais recentemente com derrames e AVCs. Contato: monique2508@gmail.com 